\title{
Temporomandibular joint disorders in patients with rheumatoid arthritis
}

\author{
Teresa Sadura-Sieklucka ${ }^{1}$ ID , Jakub Gębicki², Beata Sokołowska ${ }^{3}$, Przemysław Markowski ${ }^{4}$, \\ Beata Tarnacka ${ }^{2}$ ID \\ ${ }^{1}$ Department of Geriatrics, National Institute of Geriatrics, Rheumatology and Rehabilitation, Warsaw, Poland \\ ${ }^{2}$ Department of Rehabilitation, Faculty of Medicine, Medical University of Warsaw, Poland \\ ${ }^{3}$ Bioinformatics Laboratory, Mossakowski Medical Research Centre, Polish Academy of Sciences, Warsaw, Poland \\ ${ }^{4}$ Clinic of Rehabilitation, National Institute of Geriatrics, Rheumatology and Rehabilitation, Warsaw, Poland
}

\begin{abstract}
Objectives: The aim of this study is to draw the attention of patients, doctors and therapists to the importance of temporomandibular joint (TMJ) problems in rheumatoid arthritis (RA).

Material and methods: The research was conducted at the National Institute of Geriatrics Rheumatology and Rehabilitation in Warsaw. The study involved 60 subjects. The test group consists of 30 patients with diagnosed RA. The control group $(n=30)$ consisted of healthy participants of similar age. The study analyzed the occurrence of problems in TMJ joints, acoustic phenomena and the level of pain. Masseter muscle development, range of abduction motion and pain during palpation of soft tissues were assessed on the basis of the joint pain map of Prof. Mariano Rocabado.

Results: In the RA group, more than half (56.7\%) had problems with the TMJ, 70\% of them had masseter hypertrophy and clicks in the TMJ, and 46.7\% had tinnitus (in the control group: $10 \%, 30 \%$, and $30 \%$, respectively). Patients also had a limited range of abduction movement in the TMJ $(38.0 \pm 6.1 \mathrm{~mm})$. Analysis of the pain map of Prof. Mariano Rocabado in RA patients indicates a significantly greater number of pain structures. In the control group no pain was observed in structures such as the posterosuperior synovial and bilaminar zone, posterior ligament, or retrodiscal area. Conclusions: Temporomandibular joint problems in RA patients were more serious than in the control group and these differences were statistically significant for most tests. The awareness of the problem with the TMJ in RA patients is very low; participants of our study were $100 \%$ unaware that the function of the TMJ could be improved. Additionally, there are no guidelines for the treatment and rehabilitation of these joints.
\end{abstract}

Key words: pain, rheumatoid arthritis, temporomandibular joint, temporomandibular disorders.

\section{Introduction}

Temporomandibular disorders (TMD) are common reasons for visiting a specialist. Reports from the National Institute of Dental and Craniofacial Research indicate that the problems associated with this joint are the second most frequent complaints reported immediately after back pain [1]. They may affect as many as $5-12 \%$ of the whole population, which generates enormous costs associated with the treatment [1].
Every fifth person may have a problem with the temporomandibular joint (TMJ) of various etiologies [2]. Temporomandibular disorders cover, in a very broad sense, problems of patients in the orofacial region. Most often pain is related to dysfunction of the periarticular structures, as well as to disorders affecting the joint itself [3].

Rheumatoid arthritis (RA) is an immune-mediated inflammatory disease. Most often, the illness initially

Address for correspondence:

Beata Sokołowska, Bioinformatics Laboratory, Mossakowski Medical Research Centre, Polish Academy of Sciences, 5 Pawińskiego St., 02-106 Warsaw, Poland, e-mail: beta.sokolowska@imdik.pan.pl

Submitted: 11.05.2020; Accepted: 25.06.2021 
affects the small joints of the hands and feet. The disease affects symmetrical joints in which we observe swelling, warming and limitation of their function. Pain is a constant symptom [4].

Only very few studies pay attention to TMJ problems in patients with RA. In diagnostics of RA patients, determination of the inflammatory changes in the synovium of these joints occurred in $100 \%$ of patients, while in the control group it was only $2 \%$, which provides direct confirmation of the relationship between the disease and the joint [5].

Imaging studies such as magnetic resonance (MR) and cone beam computed tomography (CBCT) of the TMJ indicate narrowing of the joint disc and its perforation, and also a tendency to more frequent erosive changes, subchondral sclerotization and flattening of the mandible bone head $[6,7]$.

The study aims to draw the attention of patients, doctors and therapists to the importance of TMJ problems in patients with RA.

\section{Material and methods Patients}

The research was conducted at the National Institute of Geriatric Rheumatology and Rehabilitation (NIGRR) in Warsaw. It involved 60 subjects in two groups. The first group consisted of 30 patients: 23 (76.7\%) women and $7(23.3 \%)$ men with diagnosed RA.

The inclusion criteria were as follows: diagnosed RA according to the American College of Rheumatology (ACR)/European League Against Rheumatism (EULAR) criteria [8] and age in the range of 18-65 years, while we excluded from the group people who had a history of craniofacial trauma or orofacial surgery.

The second, control group (30 subjects) consisted of healthy volunteers at a comparable age to subjects in the RA group, 18 (60\%) women and 12 men (40\%). The average age for the RA group was $49.1 \pm 13.0$ (median 50), and for the control group $49.0 \pm 8.5$ (median 48) years.

The research project was approved by the Bioethics Committee of NIGRR (approval number KBT-8/9/2018), and all methods were carried out in accordance with relevant guidelines and regulations. All subjects/participants gave written informed consent for participation in the study.

\section{Methods}

To obtain general information about the age, duration of the disease and issues related to the subjective assessment of problems in the TMJ and possible therapy in this area, teeth clenching, as well as the occurrence of clicking in the TMJs and tinnitus, the relevant personal questionnaires were used.

The study used the Visual Analogue Scale (VAS) for subjective assessment of the level of pain in the examined joints. The subject examination consisted of assessing the symmetry of the head and occlusion. The study began with an evaluation of the symmetry of the occlusion as well as the quality of the lower jaw movements in the sitting position, without correction.

The position of the head in space in the sagittal and frontal plane in relation to the entire trunk was assessed. Face contour was analyzed to assess the level of masseter muscle development. In the supine position, the patients were asked to perform maximal mandible abduction (mouth opening); the measurement was performed twice with a disposable wooden spatula and the more accurate results were recorded in millimeters.

Temporomandibular joints were also palpated. The test was considered positive when it caused pain. The assessment of 8 structures was made according to the joint pain map of Prof. Mariano Rocabado, as follows: 1 - anteroinferior synovial, 2 - anterosuperior synovial, 3 - lateral collateral ligament, 4 - temporomandibular ligament, 5 - posteroinferior synovial, 6 - posterosuperior synovial, 7 - bilaminar zone or posterior ligament and 8 - retrodiscal area [9-11].

\section{Statistical analysis}

For the statistical analyses we used the STATISTICA software version 9.0 (StatSoft Inc.). Qualitative data were expressed as a count and percentages, and for the contingency tables the $\chi^{2}$ test was used, taking into account relevant corrections for this test. Quantitative data were presented as mean and standard deviation (SD), median, and range of minimum and maximum.

Due to the non-Gaussian distribution of the analyzed variables, the non-parametric Mann-Whitney $U$ test was used to analyze differences between the studied groups or various research conditions. In the correlation analysis, Spearman's rank correlation coefficient $(\rho)$ values were calculated. Probability values were considered statistically significant for $p<0.05$.

\section{Results}

Table I shows the results of the VAS pain scale analysis in both groups. In the RA group at rest, half of the participants $(n=15)$ experienced pain at an average level of $3.7 \pm 2.5$ (median 3.0), and in the control group no pain at rest was observed.

During the activities (such as yawning, eating or other movements) 18 subjects (60\%) of the RA group reported pain, the VAS increased to $5.7 \pm 2.4$ (median 6.2), 
Table I. Results for the Visual Analogue Scale

\begin{tabular}{|c|c|c|c|c|}
\hline Parameter of VAS & RA & Control & Test & $p$-value \\
\hline \multicolumn{5}{|l|}{ At rest } \\
\hline $\mathrm{VAS}=0, n(\%)$ & $15(50)$ & $30(100)$ & \multirow[t]{5}{*}{$\chi^{2}$ test (correction of $V^{2}$ ) } & \multirow[t]{5}{*}{0.00001} \\
\hline VAS > $0, n(\%)$ & $15(50)$ & $0(0)$ & & \\
\hline Mean \pm SD & $3.7 \pm 2.5$ & & & \\
\hline Median & 3.0 & & & \\
\hline (Min; Max) & $(0.2 ; 7.4)$ & & & \\
\hline \multicolumn{5}{|l|}{ During activity } \\
\hline $\mathrm{VAS}=0, n(\%)$ & $12(40)$ & $26(86.7)$ & \multirow{5}{*}{$\begin{array}{c}\chi^{2} \text { test } \\
U^{M-W} \text { test }\end{array}$} & \multirow{5}{*}{$\begin{array}{c}0.0002 \\
0.166\end{array}$} \\
\hline VAS > $0, n(\%)$ & $18(60)$ & $4(13.3)$ & & \\
\hline Mean \pm SD & $5.7 \pm 2.4$ & $3.4 \pm 3.0$ & & \\
\hline Median & 6.2 & 2.5 & & \\
\hline (Min; Max) & $(0.2 ; 9.0)$ & $(0.8 ; 7.6)$ & & \\
\hline
\end{tabular}

RA - rheumatoid arthritis, VAS - Visual Analogue Scale.

Table II. Answers to the questionnaires

\begin{tabular}{|c|c|c|c|c|}
\hline Questionnaires & $\mathrm{RA}[n(\%)]$ & Control $[n(\%)]$ & Test & $p$-value \\
\hline \multicolumn{5}{|l|}{ TMJ problems } \\
\hline Yes & $17(56.7)$ & $3(10)$ & \multirow[t]{2}{*}{$\chi^{2}$ test } & \multirow[t]{2}{*}{0.0001} \\
\hline No & $13(43.3)$ & $27(90)$ & & \\
\hline \multicolumn{5}{|l|}{ Teeth clenching } \\
\hline Yes & $19(63.3)$ & $11(36.7)$ & \multirow[t]{2}{*}{$\chi^{2}$ test } & \multirow[t]{2}{*}{0.039} \\
\hline No & $11(36.7)$ & $19(63.3)$ & & \\
\hline \multicolumn{5}{|c|}{ Expanded masseters } \\
\hline Yes & $21(70)$ & $9(30)$ & \multirow[t]{2}{*}{$\chi^{2}$ test } & \multirow[t]{2}{*}{0.002} \\
\hline No & $9(30)$ & $21(70)$ & & \\
\hline
\end{tabular}

RA - rheumatoid arthritis, TMJ - temporomandibular joint.

but only 4 people (13.3\%) experienced pain in the control group (3.4 \pm 3.0 , median 2.5 ). The observed population differences between two study groups are significant, $p=0.00001$ and $p=0002$, respectively.

In the RA group, the calculated Disease Activity Score 28 (DAS28) was equal to $5.4 \pm 1.5$ (median 5.6), which corresponds to high disease activity. It is also reflected in the levels of inflammatory parameters such as erythrocyte sedimentation rate (ESR) and C-reactive protein (CRP) serum concentration, i.e. $34.0 \pm 19.3 \mathrm{~mm} / \mathrm{h}$ (median 34) and $19.6 \pm 15.7 \mathrm{mg} / \mathrm{l}$ (median 15).

The results of the completed questionnaires are presented in Table II. They indicate that in the RA group more than half of the respondents (56.7\%) had problems in the TMJs, while in the control group only 3 subjects did so $(10 \%)$ ( $p=0.00013)$. None of the participants in either group was treated for TMD.

In the case of tooth clenching symptoms, in the RA group $63.3 \%$ of patients clench their teeth, while in the control group this symptom occurs in $36.7 \%(p=0.039)$. In turn, assessing facial symmetry in relation to the rumen muscle superstructure, muscle hypertrophy was observed in $70 \%$ of the RA patients and $30 \%$ of the healthy controls $(p=0.002)$.

Table III shows the results regarding the occurrence of acoustic phenomena (clicks) in the TMJ and tinnitus in the examined groups. In the RA group, clicks in the right temporomandibular joint (rTMJ) were observed in $60 \%$ of patients, and in the left temporomandibular joint (ITMJ) in $43.3 \%$, and clicking averages were $4.8 \pm 2.5$ (median 4.6) for the rTMJ and $5.4 \pm 1.9$ (median 4.9) for the ITMJ. In the control group only 7 subjects $(23.3 \%)$ reported clicking in the rTMJ, and in the ITMJ slightly more, 9 subjects (30\%). The number of clicks was lower: for the rTMJ about $3.6 \pm 1.9$ (median 3.0) and for the ITMJ about $3.2 \pm 1.7$ (median 2.0).

In patients with RA, tinnitus occurred in the right ear in $43.3 \%$ at the level of $4.6 \pm 2.4$ (median 4.0 ), and in the 
Table III. Results of acoustic phenomena (clicks) in the temporomandibular joint and tinnitus

\begin{tabular}{|c|c|c|c|c|}
\hline Signs & RA & Control & Test & $p$-value \\
\hline \multicolumn{5}{|c|}{ Clicks in the right TMJ } \\
\hline No, $n(\%)$ & $12(40)$ & $23(76.7)$ & \multirow[t]{2}{*}{$\chi^{2}$ test } & \multirow[t]{2}{*}{0.004} \\
\hline Yes, $n$ (\%) & $18(60)$ & $7(23.3)$ & & \\
\hline \multicolumn{5}{|l|}{ Clicks } \\
\hline Mean \pm SD & $4.8 \pm 2.5$ & $3.6 \pm 1.9$ & \multirow[t]{3}{*}{$\mathrm{U}^{M-W}$ test } & \multirow[t]{3}{*}{0.297} \\
\hline Median & 4.6 & 3.0 & & \\
\hline (Min; Max) & $(0.9 ; 10.0)$ & $(1.9 ; 7.0)$ & & \\
\hline \multicolumn{5}{|c|}{ Clicks in the left TMJ } \\
\hline No, $n(\%)$ & $17(56.7)$ & $21(70)$ & \multirow[t]{2}{*}{$\chi^{2}$ test } & \multirow[t]{2}{*}{0.284} \\
\hline Yes, $n(\%)$ & $13(43.3)$ & $9(30)$ & & \\
\hline \multicolumn{5}{|l|}{ Clicks } \\
\hline Mean \pm SD & $5.4 \pm 1.9$ & $3.2 \pm 1.7$ & \multirow[t]{3}{*}{$\mathrm{U}^{M-W}$ test } & \multirow[t]{3}{*}{0.009} \\
\hline Median & 4.9 & 2.0 & & \\
\hline (Min; Max) & $(2.7 ; 8.1)$ & $(1.9 ; 7.0)$ & & \\
\hline \multicolumn{5}{|c|}{ Summary of clicks in TMJ } \\
\hline No, $n(\%)$ & $9(30)$ & $19(63.3)$ & \multirow[t]{2}{*}{$\chi^{2}$ test } & \multirow[t]{2}{*}{0.010} \\
\hline Yes, $n(\%)$ & $21(70)$ & $11(36.7)$ & & \\
\hline \multicolumn{5}{|l|}{ Clicks } \\
\hline Mean \pm SD & $4.9 \pm 2.4$ & $3.4 \pm 1.6$ & \multirow[t]{3}{*}{$\mathrm{U}^{M-W}$ test } & \multirow[t]{3}{*}{0.074} \\
\hline Median & 4.6 & 3.0 & & \\
\hline (Min; Max) & $(0.9 ; 10.0)$ & $(1.9 ; 7.0)$ & & \\
\hline \multicolumn{5}{|c|}{ Tinnitus in the right ear } \\
\hline No, $n(\%)$ & $17(56.7)$ & $22(73.3)$ & \multirow[t]{2}{*}{$\chi^{2}$ test } & \multirow[t]{2}{*}{0.176} \\
\hline Yes, $n(\%)$ & $13(43.3)$ & $8(26.7)$ & & \\
\hline \multicolumn{5}{|l|}{ Tinnitus } \\
\hline Mean \pm SD & $4.6 \pm 2.4$ & $2.9 \pm 2.7$ & \multirow[t]{3}{*}{$\mathrm{U}^{M-W}$ test } & \multirow[t]{3}{*}{0.089} \\
\hline Median & 4.0 & 2.0 & & \\
\hline (Min; Max) & $(1.4 ; 9.0)$ & $(0.3 ; 8.0)$ & & \\
\hline \multicolumn{5}{|c|}{ Tinnitus in the left ear } \\
\hline No, $n(\%)$ & $19(63.3)$ & $22(73.3)$ & $\chi^{2}$ test & 0.405 \\
\hline Yes, $n(\%)$ & $11(36.7)$ & $8(26.7)$ & & \\
\hline Tinnitus & & & & \\
\hline Mean \pm SD & $5.2 \pm 2.5$ & $2.5 \pm 2.4$ & $\mathrm{U}^{M-W}$ test & 0.020 \\
\hline Median & 4.8 & 2.0 & & \\
\hline (Min; Max) & $(1.4 ; 9.0)$ & $(0.3 ; 8.0)$ & & \\
\hline Summary of $t$ & & & & \\
\hline No, $n(\%)$ & $16(53.3)$ & $21(70)$ & $\chi^{2}$ test & 0.184 \\
\hline Yes, $n(\%)$ & $14(46.7)$ & $9(30)$ & & \\
\hline Tinnitus & & & & \\
\hline Mean \pm SD & $4.8 \pm 2.4$ & $2.9 \pm 2.6$ & $U^{M-W}$ test & 0.063 \\
\hline Median & 4.4 & 2.0 & & \\
\hline (Min; Max) & $(1.4 ; 9.0)$ & $(0.3 ; 8.0)$ & & \\
\hline
\end{tabular}

RA - rheumatoid arthritis, TMJ - temporomandibular joint. 
Table IV. Results for abduction movement of the temporomandibular joint

\begin{tabular}{|c|c|c|c|c|}
\hline Abduction movement & RA & Control & Test & $p$-value \\
\hline \multicolumn{5}{|l|}{ Motion range (mm) } \\
\hline Mean \pm SD & $38.0 \pm 6.1$ & $45.9 \pm 5.3$ & \multirow[t]{3}{*}{$\mathrm{U}^{M-W}$ test } & \multirow[t]{3}{*}{0.000001} \\
\hline Median & 39.3 & 46.3 & & \\
\hline (Min; Max) & $(22.0 ; 49.0)$ & $(33.5 ; 60.0)$ & & \\
\hline \multicolumn{5}{|c|}{ Below the norm (< $40 \mathrm{~mm})$} \\
\hline Number (\%) & $16(53.3)$ & $4(13.3)$ & \multirow[t]{4}{*}{ (Below vs. above the norm) } & \\
\hline Mean \pm SD & $33.8 \pm 5.1$ & $37.6 \pm 2.8$ & & \\
\hline Median & 34.8 & 38.8 & & \\
\hline (Min; Max) & $(22.0 ; 39.5)$ & $(33.5 ; 39.5)$ & & \\
\hline \multicolumn{5}{|l|}{ Above the norm } \\
\hline Number (\%) & $14(46.7)$ & $26(86.7)$ & \multirow{4}{*}{$\begin{array}{c}\chi^{2} \text { test } \\
U^{M-W} \text { test }\end{array}$} & \multirow{4}{*}{$\begin{array}{c}0.001 \\
0.0005\end{array}$} \\
\hline Mean \pm SD & $42.7 \pm 2.9$ & $47.2 \pm 4.3$ & & \\
\hline Median & 41.8 & 46.8 & & \\
\hline (Min; Max) & $(40.0 ; 49.0)$ & $(41.0 ; 60.0)$ & & \\
\hline
\end{tabular}

RA - rheumatoid arthritis.

Table V. General distribution of pain-sensitive structures in the temporomandibular joint

\begin{tabular}{|lcccccc|}
\hline \multirow{2}{*}{$\begin{array}{l}\text { Pain-sensitive } \\
\text { structures }\end{array}$} & \multicolumn{4}{c}{ RA, $n$} \\
\cline { 2 - 8 } & Right TMJ & Left TMJ & Total & Right TMJ & Left TMJ & Total \\
\hline None & 8 & 10 & 18 & 18 & 15 & 33 \\
\hline Whichever & 22 & 20 & 42 & 12 & 15 & 27 \\
\hline All & 0 & 0 & 0 & 0 & 0 \\
\hline$\chi^{2}$ test & \multicolumn{7}{c}{$p=0.006$} \\
\hline
\end{tabular}

RA - rheumatoid arthritis, TMJ - temporomandibular joint.

left ear in $36.7 \%$ at the level of $5.2 \pm 2.5$ (median 4.8). In general, there were no clicks in the TMJ in $30 \%$ of RA patients and $63.3 \%$ of healthy controls ( $p=0.010)$, and no tinnitus in $53.3 \%$ of the RA group and in $70 \%$ of the control group ( $p=0.184)$.

The mean level of clicks in RA patients was higher than in healthy participants (i.e. $4.9 \pm 2.4$ and median 4.6 vs. $3.4 \pm 1.6$ and median 3.0, $p=0.074$ ). The mean number of cases of tinnitus in the RA was also higher than in the control group (i.e. $4.8 \pm 2.4$ and median $4.4 \mathrm{vs}$. $2.9 \pm 2.6$ and median 2.0, $p=0.063)$.

Analysis of the limited range of abduction motion in the TMJ (Table IV) indicates that in the RA group the range is significantly lower (mean $38.0 \pm 6.1 \mathrm{~mm}$ and median 39.3) than in the control group (mean $45.9 \pm 5.3 \mathrm{~mm}$ and median 46.3) ( $p=0.000001)$.

It was observed that only $46.7 \%$ of patients with RA achieved the range above the abduction norm (i.e. 42.7 $\pm 2.9 \mathrm{~mm}$, median 41.8). In the control group, only 4 subjects $(13.3 \%)$ did not reach the norm. The observed differences between the examined groups are significant (Table IV).
Results of the occurrence of painful structures according to the joint pain map of Prof. Rocabado are presented in Tables V-VI. As shown in Table V, RA patients have about half as many painless areas as healthy controls, and pain-sensitive structures are more common (the differences between groups are statistically significant, $p=0.006$ ). None of the studied subjects reported sensitivity at once in all pain areas of Prof. Rocabado's map.

The results presented in Table VI, which take into account the frequency of individual painful structures according to the joint pain map of Prof. Rocabado, indicate that structures numbered 1-5 are painful in both examined groups, while in the RA group they are affected more often than in the control. There was no pain in structures 6-8 in healthy individuals, and among them, structure 6, i.e. the posterosuperior synovial zone, may be of particular importance.

Moreover, in the RA group significant strong positive correlations of TMJ pain and inflammatory parameters of ESR and CRP were observed; correlation coefficient values are $\rho=0.71(p=0.0002)$ and $\rho=0.56(p=0.007)$, respectively. Significant correlations were also observed 
Table VI. Distribution of sensitive structures according to the joint pain map of Prof. Mariano Rocabado

\begin{tabular}{|lcccccc|}
\hline Name of structure & \multicolumn{3}{c}{ RA, $n$} & \multicolumn{3}{c|}{ Control, $n$} \\
\cline { 2 - 8 } & Right TMJ & Left TMJ & Total & Right TMJ & Left TMJ & Total \\
\hline 1- Anteroinferior synovial & 17 & 14 & 31 & 5 & 5 & 10 \\
\hline 2- Anterosuperior synovial & 15 & 13 & 28 & 4 & 4 & 8 \\
\hline 3- Lateral collateral ligament & 16 & 15 & 31 & 6 & 6 & 12 \\
\hline 4- Temporomandibular ligament & 21 & 17 & 38 & 8 & 10 & 18 \\
\hline 5- Posteroinferior synovial & 21 & 17 & 38 & 8 & 10 & 18 \\
\hline 6- Posterosuperior synovial & 19 & 17 & 36 & 0 & 0 & 0 \\
\hline 7- Bilaminar zone & 3 & 3 & 6 & 0 & 0 & 0 \\
\hline 8- Retrodiscal area & 1 & 0 & 1 & 0 & 0 & 0 \\
\hline Sum & 113 & 96 & 209 & 31 & 35 & 66 \\
\hline
\end{tabular}

RA - rheumatoid arthritis, TMJ - temporomandibular joint.

between the parameters of pain assessment in the joint and the abduction movement with the disease duration, i.e. the positive correlation $\rho=0.41(p=0.024)$ and the negative correlation $\rho=-0.36(p=0.048)$, respectively.

\section{Discussion}

According to the current literature, RA affects the TMJ, although the conclusions are not consistent. That may result from different research methods, diverse selection of groups and a range of their counts [12-18].

Shoohanizad et al. [19] stated that TMD occurs in autoimmune diseases such as RA, systemic sclerosis and lupus erythematosus. The analysis of articles selected by the authors indicates that the early diagnosis of problems in the TMJs slows down the progression of degenerative changes in these joints. That leads to a reduction of treatment costs. Therefore, it is recommended to conduct research on the TMD problem in relationship with connective tissue illnesses resulting from autoimmune diseases.

Our study involved 60 people, divided into two groups: patients with RA $(n=30)$ and healthy controls ( $n=30)$. In the RA group 17 patients (57\%) reported TMD, while only $3(10 \%)$ healthy individuals did so $(p=0.0001)$.

Lin et al. [20] examined a group of 17,317 patients with rheumatoid arthritis along with an equal number of controls and they found that in the RA group TMD was 2.5 times more frequent $(p<0.001)$. There was also a significant correlation of TMD in females, subjects with mental problems as well as patients after a stroke episode $(p<0.001)$. A few studies have reported the relationship between RA and the occurrence of TMJ symptoms [20-23]. It mainly manifests in the occurrence of pain, limitation of mandible movements, as well as auditory phenomena and palpation sensitivity of the joint [20-22].

A significant difference in functional mandible movement ( $p=0.000001$ ) was observed in the present study, similar to the work of Mortazavi et al. [24]. In the cited work the authors also obtained a significant result in RA patients for the occurrence of auditory phenomena $(p<0.01)$ for left and right joints.

In the study by Lin et al. [16], people with RA were also examined for TMD. They found that 13 (23\%) patients did not reach the abduction norm $(40 \mathrm{~mm})$; in our study as many as $60 \%$ of patients (18 cases out of 30 ) did so. The average range of abduction in Yi-Chun Lin's study was $42.2 \pm 0.8 \mathrm{~mm}$, while in ours it was $38.0 \pm 6.1 \mathrm{~mm}$.

Gleissner et al. [25] also observed that the RA patients achieved a lower average abduction (40.6 $\pm 6.5 \mathrm{~mm}$ ) compared to healthy subjects with an average of $45.8 \pm 5.5 \mathrm{~mm}(p<0.001)$. They obtained similar results to those described in our study for the control group, i.e. $45.9 \pm 5.3 \mathrm{~mm}$.

Alstergren et al. [26] concluded that patients with RA have a significant reduction in mandibular movement (full abduction, $p<0.001$ ).

Dev et al. [27] observed a significant reduction in the abduction movement among RA patients $(p<0.05)$; this study was conducted on older RA patients over 60 years old. The results of our study are corroborated by those of Dev et al. [27].

Regarding the level of sensitivity during rest and jaw movement, Ahmed et al. [28] found frequent occurrence of pain in the TMJ in RA patients; only 3 out of 33 (9\%) reported no complaints concerning the TMJ, while in our study 15 (50\%) subjects reported pain at rest and 18 (60\%) during activity (statistically significant differences compared to the control group, $p=0.0002$ ).

Crincoli et al. [29] noted that fewer RA patients complained about chewing pain, tinnitus and difficulty in 
opening the mouth than in the control group, which is not confirmed by our results.

In the study of Witulski et al. [6] 30\% of patients reported complaints in the TMJ area, $63 \%$ of the neck, $73 \%$ of the upper limb girdle, while only $7 \%$ out of the control group had TMJ pain. In the cited study $70 \%$ of RA patients suffered from pain during jaw movements, and $40 \%$ of patients had clicks in their joints, whereas none of the healthy people reported such complaints.

Our results confirmed the presence of TMD in RA patients. 21 patients (70\%) affirmed the occurrence of clicking in the joint, compared to only 11 (36.7\%) in the control group. 18 subjects (60\%) reported mandible discomfort, and only 4 (13.3\%) in the healthy group.

Analyzing in the anamnesis and the physical exam in 40 patients Bracco et al. [30] found that 19 of them (47.5\%) presented pain symptoms from the posterior TMJ, which is slightly lower than the number in our study, where 21 (70\%) people with RA in the right joint and $17(56.7 \%)$ in the left reported pain in this structure. Palpation of structures such as the posterosuperior synovial and bilaminar zone, posterior ligament, and retrodiscal area, according to the joint pain map of Prof. Rocabado $[9,10]$, may be crucial in differentiating between the patients and control groups because none of the healthy subjects had experienced pain in this area.

The main limitation of this study is the small size of the studied groups. Therefore these study can be considered preliminary. Further observation of the described patients and analysis of TMD cases in RA will allow to better document the problem and work out the methods of managements.

\section{Conclusions}

The TMJ problems in RA patients are more serious than in the control group and for most tests the differences were significant. The relationship between RA and TMD is confirmed in the literature. However, there is no standardized evaluation protocol that could unify the conducted research.

The awareness of the problem with the TMJ in RA patients is very low. All subjects who participated in the present study were unaware that the function of the TMJ could be improved. Additionally, there are no uniform guidelines for the treatment and rehabilitation of these joints.

The authors declare no conflict of interest.

\section{References}

1. Pihlstrom BL, Tabak L. The National Institute of Dental and Craniofacial Research: research for the practicing dentist.
J Am Dent Assoc 2005; 136: 728-737, DOI: 10.14219/jada. archive.2005.0256.

2. Gonçalves DA, Dal Fabbro AL, Campos JA, et al. Symptoms of temporomandibular disorders in the population: an epidemiological study. J Orofac Pain 2010; 24: 270-278.

3. Leeuw R, Klasser GD. Orofacial pain: guidelines for assessment, diagnosis, and management. Quintessence Publishing Co., Inc., Chicago 2019: 143-208.

4. Filipowicz-Sosnowska A. Rheumatoid arthritis. In: Clinical Rheumatology. Vol. 2, Zimmerman-Górska I (ed.). Wyd. Lekarskie PZWL, Warsaw 2008: 495-518 [Publication in Polish].

5. Sodhi A, Naik S, Pai A, Anuradha A. Rheumatoid arthritis affecting temporomandibular joint. Contemp Clin Dent 2015; 6: 124-127, DOI: 10.4103/0976-237X.149308.

6. Witulski S, Vogl TJ, Rehart S, Ottl P. Evaluation of the TMJ by means of clinical TMD examination and MRI diagnostics in patients with rheumatoid arthritis. Biomed Res Int 2014; 328560, DOI: $10.1155 / 2014 / 328560$.

7. Rehan OM, Saleh HAK, Raffat HA, Abu-Taleb NS. Osseous changes in the temporomandibular joint in rheumatoid arthritis: a cone-beam computed tomography study. Imaging Sci Dent 2018; 48: 1-9, DOI: 10.5624/isd.2018.48.1.1.

8. Aletaha D, Neogi T, Silman AJ, et al. 2010 rheumatoid arthritis classification criteria: an American College of Rheumatology/European League Against Rheumatism collaborative initiative. Ann Rheum Dis 2010; 69: 1580-1588, DOI: 10.1136/ ard.2010.138461.

9. Głuszko P, Filipowicz-Sosnowska A, Tłustochowicz W. Rheumatoid arthritis. Reumatologia 2012; 50: 83-90 [Article in Polish].

10. Rocabado Seaton M. Atlas Clinico 1. Fisiologia Articular Sinovial. Mapa del Dolor Articular Temporo Mandibular. CEDIME, Santiago L.C Chile 2011; a: 23-164 [Article in Portuguese].

11. Rocabado Seaton M. Atlas Clinico 2. Congruencia CraneoCervico Mandibular. Aplicacion Practica Clinica. CEDIME, Santiago L.C. Chile 2011; b: 18-40 [Article in Portuguese].

12. Wetselaar P, Vermaire EJH, Lobbezoo F, Schuller AA. The prevalence of awake bruxism and sleep bruxism in the Dutch adult population. J Oral Rehabil 2019; 46: 617-623, DOI: 10.1111/ joor.12787.

13. Torkzaban P, Hjiabadi T, Basiri Z, Poorolajal J. Effect of rheumatoid arthritis on periodontitis: a historical cohort study. J Periodontal Implant Sci 2012; 42: 67-72, DOI: 10.5051/jpis. 2012.42.3.67.

14. Scrivani SJ, Keith DA, Kaban LB. Temporomandibular disorders. N Engl J Med 2008; 359: 2693-2705, DOI: 10.1056/NEJMra0802472.

15. Goupille P, Fouquet B, Cotty P, et al. The temporomandibular joint in rheumatoid arthritis. Correlations between clinical and computed tomography features. J Rheumatol 1990; 17: 1285-1291.

16. Lin YC, Hsu ML, Yang JS, et al. Temporomandibular joint disorders in patients with rheumatoid arthritis. J Chin Med Assoc 2007; 70: 527-534, DOI: 10.1016/S1726-4901(08)70055-8.

17. Cordeiro PC, Guimaraes JP, de Souza VA, et al. Temporomandibular joint involvement in rheumatoid arthritis patients: association between clinical and tomographic data. Acta Odontol Latinoam 2016; 29: 123-129. 
18. Isola G, Perillo L, Migliorati M, et al. The impact of temporomandibular joint arthritis on functional disability and global health in patients with juvenile idiopathic arthritis. Eur J Orthod 2019; 41: 117-124, DOI: 10.1093/ejo/cjy034.

19. Shoohanizad E, Garajei A, Enamzadeh A, Yari A. Nonsurgical management of temporomandibular joint autoimmune disorders. AIMS Public Health 2019; 6: 554-567, DOI: 10.3934/ publichealth.2019.4.554.

20. Lin $\mathrm{CY}$, Chung CH, Chu HY, et al. Prevalence of temporomandibular disorders in rheumatoid arthritis and associated risk factors: a nationwide study in Taiwan. J Oral Facial Pain Headache 2017; 31: e29-e36, DOI: 10.11607/ofph.1917.

21. Celiker R, Gökçe-Kutsal Y, Eryilmaz M. Temporomandibular joint involvement in rheumatoid arthritis. Relationship with disease activity. Scand J Rheumatol 1995; 24: 22-25, DOI: 10.3109/03009749509095149.

22. Kurtoglu C, Kurkcu M, Sertdemir Y, et al. Temporomandibular disorders in patients with rheumatoid arthritis: a clinica study. Niger J Clin Pract 2016; 19: 715-720, DOI: 10.4103/11193077.164343.

23. Bessa-Nogueira RV, Vasconcelos BC, Duarte AP, et al. Targeted assessment of the temporomandibular joint in patients with rheumatoid arthritis. J Oral Maxillofac Surg 2008; 66: 18041811, DOI: 10.1016/j.joms.2007.08.037.

24. Mortazavi N, Babaei M, Babaee N, et al. Evaluation of the prevalence of temporomandibular joint involvement in rheuma- toid arthritis using research diagnostic criteria for temporomandibular disorders. J Dent (Tehran) 2018; 15: 332-338.

25. Gleissner C, Kaesser U, Dehne F, et al. Temporomandibular joint function in patients with longstanding rheumatoid arthritis $-I$. Role of periodontal status and prosthetic care a clinical study. Eur J Med Res 2003; 8: 98-108.

26. Alstergren P, Pigg M, Kopp S. Clinical diagnosis of temporomandibular joint arthritis. J Oral Rehabil 2018; 45: 269-281, DOI: 10.1111/joor.12611.

27. Dev S, Perti S, Garhnayak M, et al. Intricate estimation and evaluation of mandibular movements in geriatric patients suffering from rheumatoid arthritis. J Contemp Dent Pract 2017; 18: 781-784, DOI: 10.5005/jp-journals-10024-2126.

28. Ahmed N, Mustafa HM, Catrina Al, Alstergren P. Impact of temporomandibular joint pain in rheumatoid arthritis. Mediators Inflamm 2013; 2013: 597419, DOI: 10.1155/2013/ 597419.

29. Crincoli V, Anelli MG, Quercia E, et al. Temporomandibular disorders and oral features in early rheumatoid arthritis patients: an observational study. Int J Med Sci 2019; 16: 253-263, DOI: 10.7150/ijms.28361.

30. Bracco P, Debernardi C, Piancino MG, et al. Evaluation of the stomatognathic system in patients with rheumatoid arthritis according to the research diagnostic criteria for temporomandibular disorders. Cranio 2010; 28: 181-186, DOI: 10.1179/ crn.2010.025. 